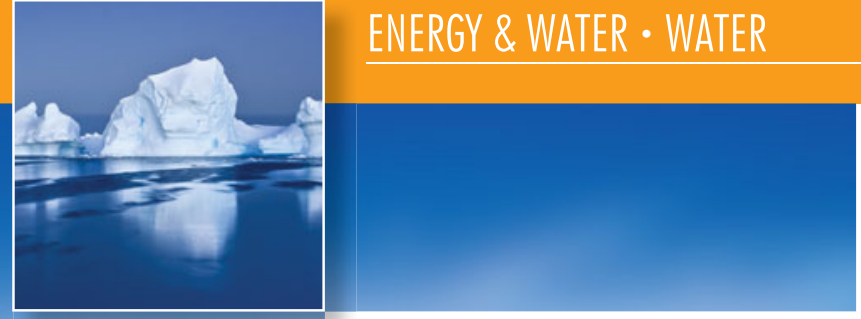

\title{
The energy-walter nexus: Waiter use trends in sustainable energy and opportunities for materials research and development
}

\author{
Anthony Y. Ku and Andrew P. Shapiro
}

Over the next few decades, the challenge of water scarcity is expected to grow more acute as water demands from the power generation, agriculture, industrial, and municipal sectors all increase. Energy production requires copious amounts of water, with the volume of water used by power generation ranking second only to that used for agriculture. This article reviews options for managing the water requirements associated with power generation. Although the effects of both existing and emerging modes of power generation on water use trends are explored, the primary focus is on thermal systems, which account for the majority of existing capacity.

\section{Introduction}

Global electricity demand is projected to increase strongly over the next several decades. Efforts to build the energy infrastructure needed to meet this demand must reflect (1) regional differences in economic growth rates and energy resources, (2) policy and social considerations such as safety, (3) environmental concerns such as ecosystem health and climate change, (4) the technological maturity of various options, and (5) the availability of sufficient supplies of water. ${ }^{1}$ This article focuses on the last aspect, as many forms of power generation, including the dominant modes used today, require copious amounts of water. The largest use of water in power generation, by far, is for the removal of waste heat.

Currently, global water use in power generation ranks second only to that in agriculture, although there is wide variation between countries. The challenges posed by water scarcity are expected to grow more acute because of increasing demand from the power generation, agriculture, industrial, and municipal sectors. Indeed, in the past decade, drought conditions have forced nuclear power plants in France and the southeastern United States to curtail power generation on several occasions. ${ }^{2}$ Managing the competition for water will be one of the major challenges facing policy makers, industry leaders, and technologists as they work toward the goal of sustainable development. ${ }^{3}$
The research and development (R\&D) needs at the interface between energy $\mathrm{y}^{4,5}$ and water treatment ${ }^{6}$ present a wide range of opportunities that can be addressed by the materials research community. This article provides a framework for prioritizing materials R\&D efforts in water use for electricity generation. The discussion is divided into three parts. The first section reviews trends in power generation and water use and introduces a metric for comparing different technologies. The second section focuses on water use in power plants and considers ways in which materials innovations can reduce water demand. These include improving the efficiency of gas and steam turbines through the development of next-generation superalloys, high-temperature materials such as ceramic matrix composites, and hydrophobic condenser surfaces. Because cooling accounts for the majority of water use in thermal systems, lower-cost heat-transfer materials can improve the economic competitiveness of air-cooled condensers and other low-water-demand cooling options. The final section addresses ways in which materials R\&D can help to expand the supply of water suitable for power-generation use, particularly for cooling in thermal plants. Nontraditional water sources such as brackish aquifers and produced water from oil and gas operations have a higher tendency to foul equipment, and materials advances such as biofilm resistance coatings and membranes have the potential to enable the use of these water resources for cooling. 


\section{Water use trends and metrics}

Figure 1 provides a snapshot of global power generation and its associated water footprint. Thermal processes, which generate electricity from heat, account for almost $80 \%$ of total generating capacity - including fossil-fuel, nuclear, geothermal, solar-thermal, and biomass sources. A necessary step in these cycles is the rejection of lower-grade waste heat to the environment, for which water-based methods are among the most effective. As discussed in the next section, water use for cooling is the major driver for demand. ${ }^{8,9}$

The sidebar provides a detailed look at water demands from power generation and how they could evolve over the next few decades. Water usage is expected to increase because of increased power generation. According to U.S. Energy Information Administration (EIA) projections, the single largest driver will be the growth of coal-fired capacity in Asia, especially China. ${ }^{9,12}$ Improvements in plant efficiency through new technology and consolidation could drive down specific water use, as would the maturation and adoption of less-water-demanding renewable energy technologies
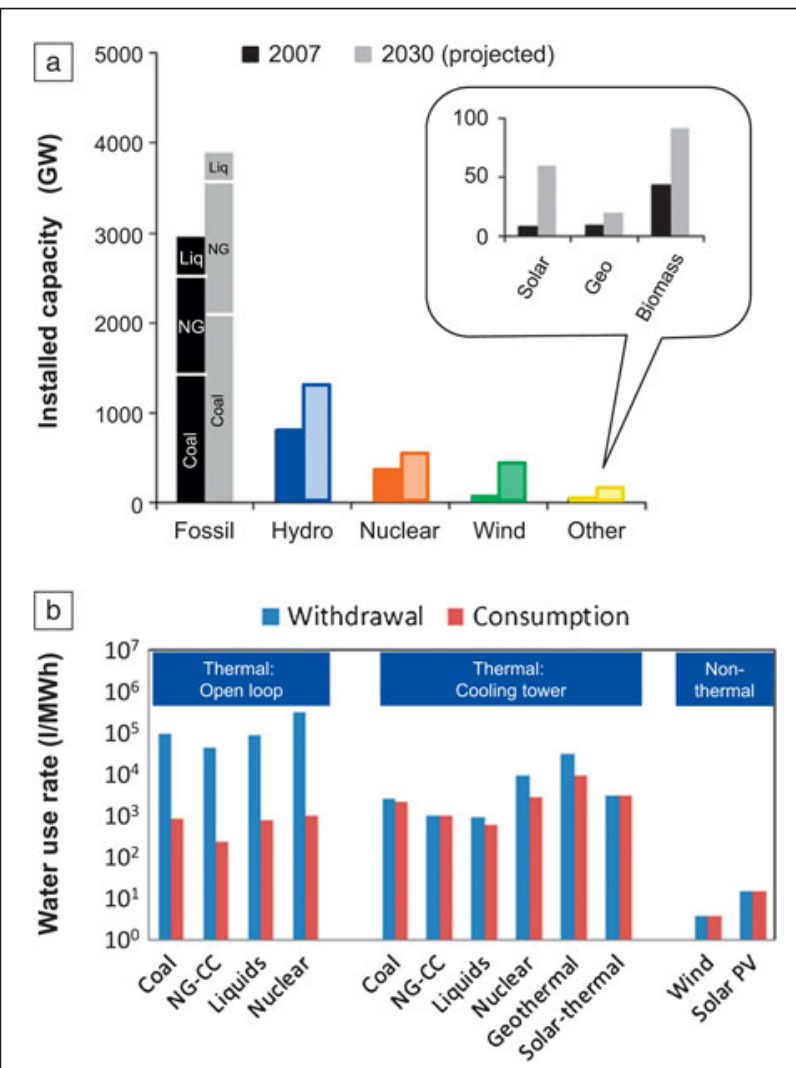

Figure 1. (a) Current global installed capacity for different modes of power generation and (b) average specific water withdrawal and consumption rates for power generation modes. (Consumed water refers to the fraction of withdrawn water that is not available after use.) For a more detailed breakdown of the ranges for water use rates, see Reference 7. Abbreviations: Geo, geothermal; Liq, liquids (e.g., oil); NG, natural gas; NG-CC, natural gas combined cycle; PV, photovoltaics. The water footprint of hydroelectric power is not shown, as there is some debate as to the exact nature of the water use. such as wind and solar. Conversely, the widespread adoption of carbon capture technologies for fossil-fuel-based power could increase specific water use.

The most significant distinction in water use is between thermal and nonthermal systems. Among thermal modes, water consumption further depends on how the water is used for cooling. In once-through (or open-loop) cooling, water is withdrawn from a source and returned at a higher temperature. In contrast, cooling-tower-based approaches require much lower withdrawal rates, because a significant amount of heat is removed by evaporation. Both cooling modes are discussed in detail in the next section.

Among nonthermal processes, hydroelectric power has the largest installed capacity, ranking third among the power modes. There is debate as to the ultimate rates of water usage by hydroelectric power: Some reports focus on the higher evaporation rates from reservoirs created by dams, whereas others note that most of the water is returned for downstream use. ${ }^{8}$ Wind is the next-largest nonthermal generation mode, accounting for about $2 \%$ of global capacity. Installed capacity for photovoltaic solar generation is currently small but growing rapidly. Both wind and solar power use water for cleaning of equipment during operation, but their largest water footprints are associated with manufacturing. ${ }^{8}$

Several metrics are used to track water use in power generation: Water withdrawal rate refers to all water removed from a source, some of which could be returned, whereas water consumption rate refers to the fraction of withdrawn water that is not available after use. Some authors also calculate energy return on water invested from a life-cycle assessment of water use. ${ }^{13}$ In this article, we compare alternate technologies using a monetary metric, the cost of conserved water (CCW), defined as ${ }^{14}$

$$
\operatorname{CCW}\left(\$ / \mathrm{m}^{3}\right)=\frac{\Delta \operatorname{LCOE}(\$ / \mathrm{MWh})}{\Delta \mathrm{WD}\left(\mathrm{m}^{3} / \mathrm{MWh}\right)},
$$

where $\triangle \mathrm{LCOE}$ is the difference in the levelized cost of electricity (LCOE) between the alternate power generation system and a baseline pulverized-coal plant employing cooling towers that withdraw surface water and $\triangle \mathrm{WD}$ is the reduction in specific water withdrawal rate between the same two systems. The LCOE accounts for the cost of power generation over the lifetime of the power plant, including both initial capital investments and fuel costs. The cost of conserved water is a simple way to rate the economic impact of adopting less-water-intensive technology against the local cost of water. If water is relatively abundant and inexpensive, it makes economic sense to simply use it for evaporative or once-through cooling. In regions where water is scarce, the higher cost of water can justify the deployment of alternatives.

Several approaches can improve water utilization in power production. This article focuses solely on thermal processes, because of their dominant share of electricity generation; ${ }^{15}$ nonthermal processes are discussed in Reference 8. On the demand side, this means reducing the cost of conserved 
water by decreasing specific water use through (1) the use of alternate cooling fluids such as air and (2) increased power-plant efficiency. A complementary approach is to tap nontraditional water resources. Seawater, brackish aquifers, processed municipal wastewater, produced water from hydrocarbon extraction, and abandoned mine drainage are all potential sources that could conserve freshwater for other uses. Materials breakthroughs can help in each of these areas, but it is necessary to critically evaluate where investment is justified, as not all opportunities have equal potential impacts.

As a concrete example of how the cost of conserved water can be used to benchmark the competitiveness of a watersaving technology, consider air-cooled condensers (ACCs), which are being deployed as an alternative to wet cooling. The U.S. Department of Energy (DOE) estimated that, for a 500-MW subcritical pulverized-coal plant, this technology increases the LCOE by $\$ 3.50 / \mathrm{MWh}$, while eliminating $\sim 90 \%$ of water withdrawals (2300 1/MWh). ${ }^{14}$ Substituting these values into Equation 1 gives a CCW of about $\$ 1.50 / \mathrm{m}^{3}$, so dry cooling becomes economically competitive where the cost of available water is more than this. Put another way, ACC technologies have the potential to reduce water use in coal plants by up to $90 \%$ but result in an increase of about $5 \%$ in the LCOE. ${ }^{16}$

Table I compares water costs from the United States and China and provides context for the economic competitiveness of the alternate cooling technology. ACC water "costs" are at the high end of the range for both U.S. and Chinese water supplies. The economics become more favorable in arid regions and can also be improved through technology innovation. U.S. DOE R\&D programs call for a reduction in the cost of alternate cooling for existing plants by $25 \%$ to $\$ 1.15 / \mathrm{m}^{3}$ of water conserved by 2015 and by $50 \%$ to $\$ 0.75 / \mathrm{m}^{3}$ of water conserved by $2020 .{ }^{14}$ Success in achieving these targets would significantly improve the economic competitiveness of non-water-based cooling technologies.

\section{Options for reducing water demand}

Any survey of options for reducing water demand must begin with the drivers for water use. Given the dominant role of thermal processes in electricity generation, a useful starting point is the thermodynamics of power plants. Thermal processes used for power production require a heat source and a lower-temperature heat sink. The maximum efficiency, $\eta$, of any thermal cycle is the Carnot efficiency,

$$
\eta=\frac{\text { work produced }}{\text { thermal energy input }}=\frac{T_{\mathrm{h}}-T_{\mathrm{c}}}{T_{\mathrm{h}}},
$$

where $T_{\mathrm{h}}$ is the temperature of the heat source and $T_{\mathrm{c}}$ is the temperature of the heat sink. The Carnot efficiency is maximized by high-temperature sources and low-temperature sinks. Heatsource temperatures are usually limited by material constraints (e.g., maximum temperature for combustors and turbine blades in gas turbines). Heat-sink temperatures are set by local climate and water availability.

In practice, about $80 \%$ of all electricity is produced using steam turbines configured in a Rankine cycle. In a Rankine cycle, the heat-sink temperature is governed by the steam condenser. For maximum power output and efficiency, the

\begin{tabular}{|c|c|c|c|}
\hline Water option & Cost of water & Notes & Reference \\
\hline \multicolumn{4}{|c|}{ Air-cooled condensers: Cost of conserved water } \\
\hline Baseline & US $\$ 1.50 / \mathrm{m}^{3}$ & U.S. Department of Energy estimate, 2008 & 14 \\
\hline Target for 2015 & US $\$ 1.15 / \mathrm{m}^{3}$ & $25 \%$ savings versus baseline & 14 \\
\hline Target for 2020 & US $\$ 0.75 / \mathrm{m}^{3}$ & $50 \%$ savings versus baseline & 14 \\
\hline \multicolumn{4}{|c|}{ North America: U.S. supply (2007) } \\
\hline Municipal & & US $\$ 0.30-2.30 / \mathrm{m}^{3}$ & 17 \\
\hline Industry & & US $\$ 0.30-1.80 / \mathrm{m}^{3}$ & 17 \\
\hline Agriculture & & US $\$ 0.01-1.50 / \mathrm{m}^{3}$ & 17 \\
\hline \multicolumn{4}{|c|}{ Asia: China supply (2008) ${ }^{\mathrm{a}}$} \\
\hline Municipal & US\$0.15-1.00/m³ & $1-6.9 \mathrm{RMB} / \mathrm{m}^{3}$ & 18 \\
\hline Industry & US\$0.22-1.00/m³ & $1.5-6.9 \mathrm{RMB} / \mathrm{m}^{3}$ & 18 \\
\hline Agriculture & US\$0.01-0.07/m³ & $0.1-0.5 \mathrm{RMB} / \mathrm{m}^{3}$ & 18 \\
\hline \multicolumn{4}{|c|}{ Water treatment } \\
\hline Desalination (brackish) & US $\$ 0.45 / \mathrm{m}^{3}$ & Total dissolved solids of $8000-1000 \mathrm{ppm}$ & 17 \\
\hline Desalination (seawater) & US $\$ 0.53-0.65 / \mathrm{m}^{3}$ & Reverse-osmosis membrane & 17 \\
\hline Desalination (seawater) & US\$0.77-1.14/m³ & Multistage flash & 17 \\
\hline
\end{tabular}
condenser should be as cool as possible. In a typical steamturbine system, the condenser is cooled to about $40^{\circ} \mathrm{C}$, so the condensed steam is under a vacuum $(\sim 0.1$ bar absolute) . This low condenser pressure is transmitted to the last stage of the steam turbine and governs how much power can be produced. The heat at $40^{\circ} \mathrm{C}$ is truly waste heat, as it is presently uneconomical to extract more work from it.

Condensers are cooled by water or air. The choice depends on the local climatic, environmental, and regulatory conditions. Water-cooled condensers are smaller and less expensive, and they provide lower, more stable temperatures than air-cooled condensers, but their water requirements are greater. 
When surface water is available and regulations allow, oncethrough water cooling is usually the most cost-effective solution. ${ }^{19}$ In once-through cooling systems, water is withdrawn from the source, pumped through the condenser, and returned to the source at a higher temperature (typically $10-15^{\circ} \mathrm{C}$ warmer). For a 33\% efficient Rankine cycle, each megawatt of power production requires approximately $30 \mathrm{l} / \mathrm{s}$ of water withdrawals. A 500-MW plant withdraws nearly $1.4 \times 10^{6} \mathrm{~m}^{3} /$ day $[250,000$ gallons per minute (gpm)] of water.

Plants that use cooling towers withdraw less water but consume more, relative to once-through systems. Cooling towers remove heat primarily through evaporation after the water has been heated in the condenser. A typical cooling tower evaporates $0.5 \mathrm{l} / \mathrm{s}$ of water per megawatt of generated power. To prevent salts from building up in the cooling water, a "blowdown" stream comprising concentrated salts is also removed from the cooling loop. This blowdown typically accounts for $10-20 \%$ of the total water consumption. A 500MW plant consumes approximately $26,000 \mathrm{~m}^{3} /$ day $(4800$ gpm) of water.

The two main themes for reducing water demand for power-plant cooling through materials innovations are developing alternate cooling fluids to replace water and improving thermal efficiency in the turbine. Following the first approach, air or hybrid cooling can eliminate most of the water demand, but progress is needed to make these approaches economical. To increase power-plant efficiency, specific materials needs include next-generation superalloys and coatings for higher-temperature gas and steam turbines.

\section{Air cooling}

Air-cooled condensers (ACCs) work by blowing ambient air over a set of finned condenser coils. Because of the lower heat capacity and density of air compared to water, the heat-transfer area of an ACC is 20-50 times larger than that of a water-cooled condenser. In addition, ACCs penalize power-plant performance more than water-cooled condensers, because the air is usually much warmer than local water. This problem is particularly acute in warm locations, where the power demand peaks during the hottest part of the day.

As discussed in the previous section, cost reductions on the order of $25-50 \%$ are needed for ACCs to become economically competitive in most regions of the world. The footprints and heights of current ACC configurations are about twice those of conventional cooling towers, leading to twice the capital cost. ${ }^{14,20} \mathrm{R} \& \mathrm{D}$ efforts are progressing on several fronts, including more compact designs that use less material and the development of wind-guide technology to better manage performance under changing ambient conditions. ${ }^{19}$

\section{Improved efficiency in the steam cycle}

Increasing the thermal efficiency of power plants is another way to reduce water demand. In a Rankine-cycle plant (see Figure 2), the working fluid (usually water) is pumped to high pressure in the liquid state and heated in a boiler to create high-pressure, high-temperature vapor. The vapor expands through a turbine, generating power, and then condenses back to a liquid by rejecting heat to the environment in a condenser, which is where most of the water is used. The cooled liquid is then pumped back to high pressure, completing the cycle.

Thermal efficiencies over $45 \%$ have been achieved by increasing the steam temperature and pressure to supercritical $\left(600^{\circ} \mathrm{C}, 250 \mathrm{bar}\right)$ and ultrasupercritical $\left(720-760^{\circ} \mathrm{C}, 340\right.$ bar) conditions. Because water usage in a thermal power plant scales inversely with efficiency, shifting to supercritical plants could reduce water usage by $27 \%$ compared to the installed base. ${ }^{21}$ Materials are needed for next-generation turbine components, because advanced 9-12Cr martensitic-ferritic steels approach their operating limit at around $620^{\circ} \mathrm{C} .{ }^{22} \mathrm{Nickel}$ and nickel-cobalt superalloys offer the necessary creep strength and steam oxidation resistance for steam turbine blades and heat-transfer surfaces that operate near and above $700^{\circ} \mathrm{C}$, but development is needed to bring down manufacturing costs. Austenitic stainless steels and alloys offer designers an intermediate option, with temperature capabilities between those of existing steels and nickel-based superalloys but at lower cost than superalloys.

Materials advances can also improve the operation of condensers in steam cycles, leading to both economic benefits and reductions in water use. Laboratory studies have shown that hydrophobic and superhydrophobic surfaces improve heat-transfer rates by promoting dropwise condensation over film condensation. ${ }^{23}$ The benefits of higher heattransfer coefficients would be accrued mainly through cost savings due to smaller heat exchangers. Savings in water use

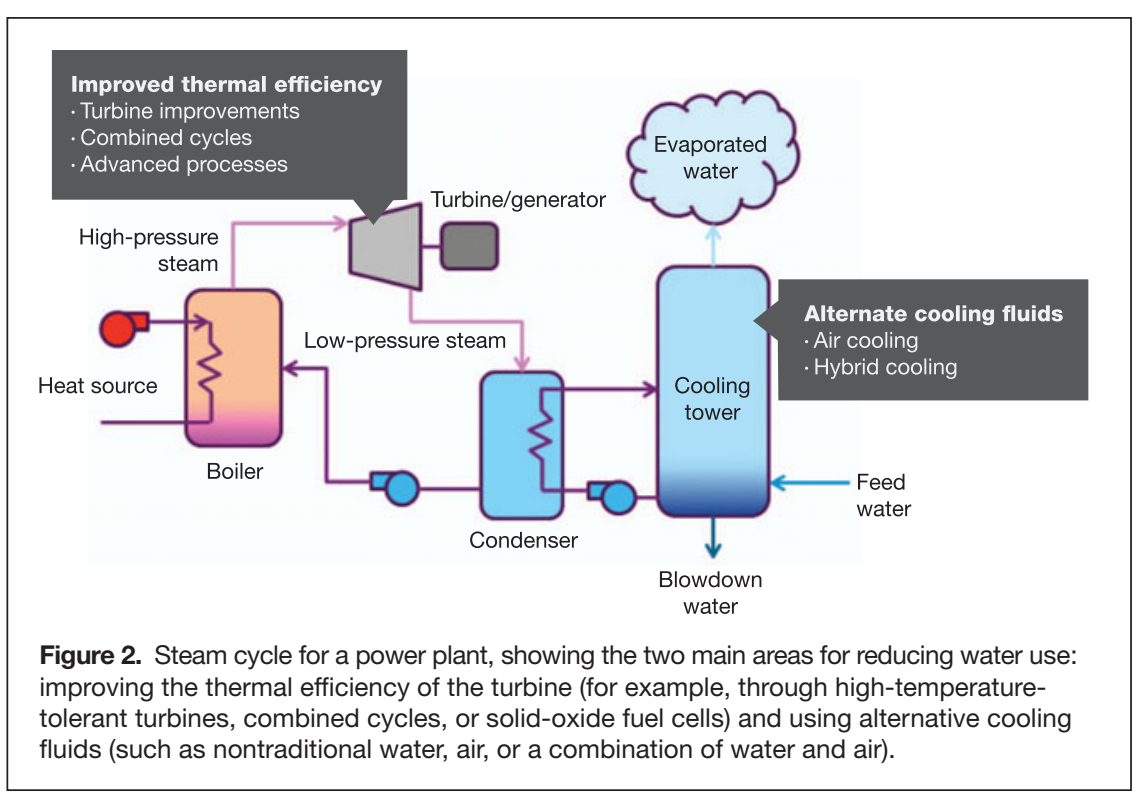


are possible if the improved heat transfer leads to lower temperatures and pressures on the vapor side of the condenser. This would increase the power and efficiency of the plant. To date, most studies have used organic coatings, and work is needed to move to more robust materials for energy applications. Efforts to develop inorganic coatings with hydrophobic properties are still at a relatively early stage. ${ }^{24}$

\section{Gas-turbine and combined-cycle plants}

Further water savings can be achieved by using power cycles that do not require cooling water. After steam turbines, gas turbines are the most productive power-generation method. They operate with much higher heat-source temperatures than steam turbines and, therefore, higher efficiencies. In a simple gas-turbine, or Brayton, cycle, the exhaust is released to the environment after passing through the turbine and a recuperative heat exchanger. No cooling water is required, although water is often used to cool the inlet air for power augmentation and to provide a diluent for combustion to control $\mathrm{NO}_{x}$ formation. As examples, wet $\mathrm{NO}_{x}$ control uses approximately $0.05 \mathrm{l} / \mathrm{s}$ of water per megawatt of generated power, and steam injection for power augmentation uses about $0.1-0.2 \mathrm{l} / \mathrm{s}$ per megawatt of generated power. ${ }^{25,26}$

In a combined-cycle power plant, the exhaust from the gas turbine is used to generate steam that runs a steam turbine. Thermal efficiency in combined-cycle systems approaches $60 \%$, with the gas turbines accounting for about $65 \%$ of the total electrical generating capacity. Because most of the water use is for cooling the steam-turbine condenser, the specific water usage of combined-cycle plants is about $35 \%$ that of a simple steam turbine plant (see Figure 3). For a 500-MW plant, this is about $9300 \mathrm{~m}^{3} /$ day (1700 gpm).

\section{Materials opportunities}

As with steam turbines, an important path toward increased efficiency in gas turbines is the use of turbine blades and

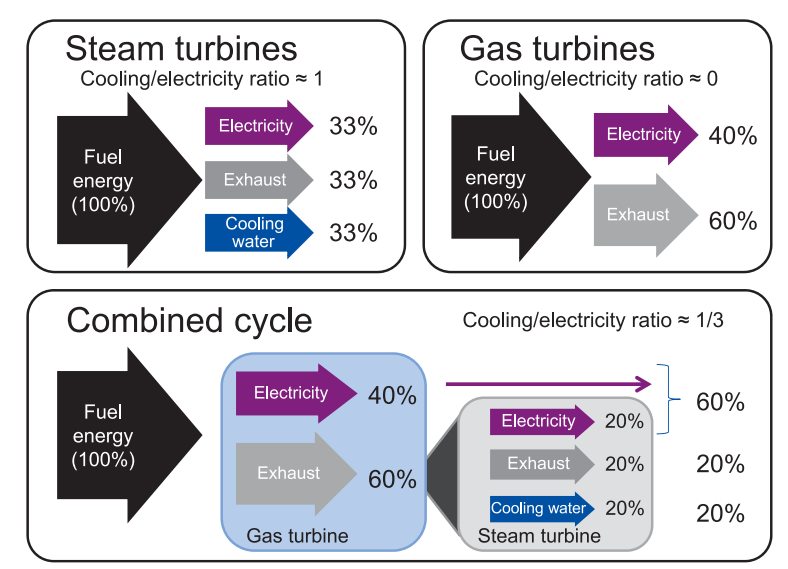

Figure 3. Allocations of energy in Rankine (steam turbine) and Brayton (gas turbine) thermodynamic cycles and in a combined cycle that uses the high-temperature exhaust from the Brayton cycle as input for the Rankine cycle. other hot-path components capable of operating at higher temperatures and pressures. Today's most advanced blades comprise single-crystal, directionally solidified nickel-based superalloys containing rhenium. ${ }^{16}$ Through the use of ceramic thermal-barrier coatings and advanced designs capable of delivering appropriate cooling, these blades can function at gas temperatures above the melting point of the superalloy, or about $1300^{\circ} \mathrm{C} .{ }^{27}$ In addition to improved mechanical properties (e.g., creep strength, oxidation resistance, and hot corrosion resistance), superalloy-related materials development efforts are focused on reducing manufacturing costs through improved process control and the formulation of alloys with reduced amounts of expensive elemental components such as rhenium (see the article in this issue by Konitzer et al.). An alternate path toward high-temperature-capability materials involves the use of ceramic matrix composites. ${ }^{28}$ As with superalloys, development efforts are split between improving mechanical properties and reducing manufacturing costs.

In the longer term, further gains are possible using emerging technologies such as high-temperature fuel cells. Solidoxide fuel cells can be combined with gas turbines or other engines to achieve even higher thermal efficiencies, further reducing the cooling water requirements. ${ }^{29}$ Current R\&D efforts in this area seek to increase current densities and improve reliability through engineering of the cell and stack components and to reduce costs by optimizing the manufacturing process. ${ }^{30}$

\section{Options for increasing water supply}

An important feature of the supply-side dynamic is that water is sometimes available in the form of nontraditional sources that require treatment before use. Examples include brackish aquifers, municipal wastewater, produced water from hydrocarbon extraction processes, and acidic mine-pool waters. In 2006, the U.S. DOE set a goal of increasing the current utilization rate of about $8 \%$ to $25 \%$ within 10 years and has funded a range of activities including cataloguing potential sources, developing treatment technologies, and evaluating system integration issues. $^{19}$

Materials innovations can contribute to expanded use of nontraditional water supplies in two ways. The first involves upgrading the water quality to match that of existing fresh water supplies. This includes removing problematic components, reducing variability, and improving the robustness of treatment equipment to handle "impaired" water. A second approach is to improve the ability of cooling systems to directly use impaired water. In both cases, the goal is to make the cost of the treated water competitive with that of freshwater or alternate cooling technologies.

\section{Upgrading nontraditional water quality}

Water used for cooling in thermal systems must be treated to manage scale deposition, fouling through biofilm formation, and corrosion. In freshwater systems, these challenges 
are managed through chemical additives, along with careful operation of the cooling system. Nontraditional water resources present two challenges. First, they can contain elevated concentrations of components that can foul or damage equipment. Examples include (1) dissolved hardness or silica (brackish water) leading to enhanced scaling tendencies, (2) residual organics (municipal wastewater or produced water) leading to elevated microbiological activity, and (3) extremes in $\mathrm{pH}$ (acidic mine pools) leading to accelerated corrosion. Second, the water volumes and quality, especially from natural aquifers or hydrocarbon extraction operations, can vary with time, making it difficult to achieve stable performance. Variability also increases maintenance requirements and, consequently, the cost of treatment. Table II summarizes typical water-quality requirements for cooling towers and the challenges posed by several nontraditional water resources. ${ }^{28}$

Multiple technologies exist for improving nontraditional water quality:

- Chemical additives act in a variety of ways, including inhibiting precipitation and biological activity or altering interfacial properties.

- Gravity-based separations, such as settling tanks and flotation processes, separate particulate matter (includ- ing chemically precipitated components) using density differences.

- Membranes and filters physically exclude one or more components on the basis of size or solubility.

- Electrical processes remove charged particles as well as dissolved ions.

- Thermal evaporation processes such as distillation produce clean water through evaporation and condensation.

These technologies can be used individually or in concert. Field experience has shown that the most effective configurations typically involve multiple treatment steps, selected based on local conditions. ${ }^{31}$ Table II also rates the watertreatment options against the various nontraditional water sources.

Materials breakthroughs can improve the performance and economics of many of these technologies. Figure 4 shows some recent examples for membranes. Membranes are typically classified according to pore size. In general, reducing the pore size improves the selectivity but diminishes the flux. Membranes with pores in the range of micrometers to tens of nanometers are used to remove suspended solids, emulsified oil, microbes, and colloidal material through microfiltration or ultrafiltration processes. Smaller pores, such as those in the nanometer range, can allow removal of multivalent ions and some biological molecules through a nanofiltration process. Reverse-osmosis membranes are used to remove dissolved salts as part of a desalination process.

A wide range of activities are underway to improve the permeability of reverse-osmosis membranes. ${ }^{32,33}$ One approach involves the modification of commercial membrane materials to adjust their surface charge or to attach molecules that sterically hinder the adsorption of foulants (Figure 4a). Another interesting direction involves new membrane materials based on carbon nanotubes or aquaporin proteins. Laboratory studies suggest that these materials have the potential to increase permeability by up to two or three orders of magnitude over those of conventional polymer materials (Figure 4b). ${ }^{34-36}$ In both cases, the underlying idea is to incorporate the carbon nanotubes or protein into a polymer matrix to provide 


\section{a Modifications of conventional materials}

(surface charge, steric effects)

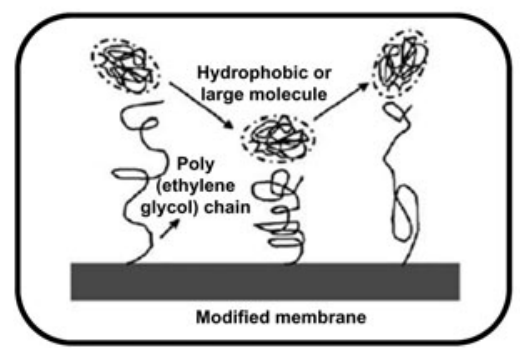

b Carbon nanotube based membranes

(up to $1000 \times$ flux enhancement)

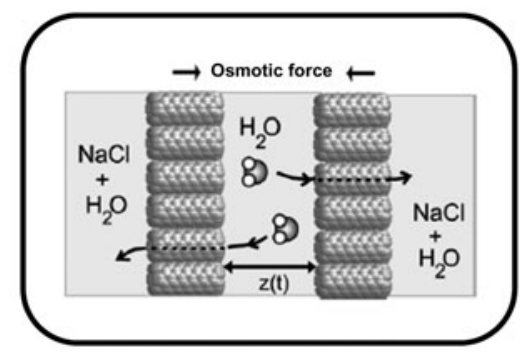

c

\section{Aquaporin/ protein membranes}

(up to $100 \times$ flux enhancement)

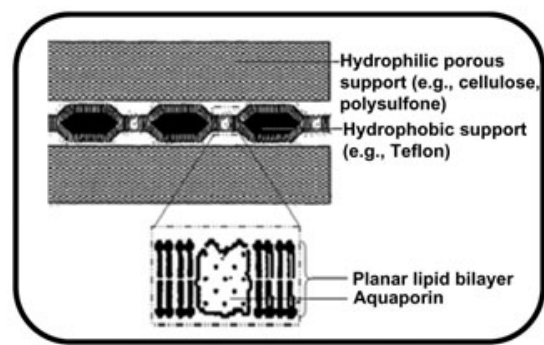

Figure 4. Innovative concepts for improving flux in reverse-osmosis membranes: (a) modification of conventional polymeric materials, (b) carbon nanotubes, (c) aquaporins and protein-based membranes. Parts a-c adapted with permission from References 33, 34, and 32, respectively.

pathways for water transport. A key challenge is to maximize the loading while also ensuring that the water-transport pathways are accessible. Further work is also needed to validate membrane performance under realistic operating conditions, improve the manufacturability of the materials, and develop integrated modules for field testing. Success could lower the cost of desalination by reverse-osmosis membranes, but further analysis is needed to quantify the potential benefits.

\section{Improving the robustness of cooling equipment}

An alternative approach to utilizing nontraditional water is to modify existing equipment to accept it. Over the past decade, there has been considerable work on coatings with modified surface properties that could be useful for this application. For example, wet-surface air coolers are hybrid water-cooling systems that direct a co-current flow of air and water droplets over closed-loop cooling tubes. A uniform distribution of water over the tubes is essential to minimize scale deposition. ${ }^{37,38}$ To this end, surface-energy modifications through the use of hydrophilic or superhydrophilic coatings could promote wetting to help manage scaling problems and prevent oil deposition. As with the hydrophobic and superhydrophobic surfaces discussed earlier for condensers, the primary materials issues relate to durability under field conditions.

A second area of interest is developing heat-transfer materials with improved resistance to biofouling and saltwater corrosion. Insights from work in marine applications could provide the basis for advanced coatings technologies that could be useful for power-plant cooling. ${ }^{39}$ Such coatings are typically polymeric surfaces intended to resist biofouling by resisting initial protein adsorption or by reducing the adhesion of biofilms to the heat-transfer surfaces. For example, hydrophobic polymers such as polydimethylsiloxane (PDMS) have shown "fouling release" tendencies, and hydrophilic polymers resist protein adsorption. Work is needed to tailor materials for the specific extracellular polymeric substances secreted by microorganisms encountered in power-plant environments. Coating robustness is also an open question.

Finally, recent work with nontraditional materials of construction such as polymers or composites could also be promising. ${ }^{40}$ Such materials offer different surface chemistries that could prove beneficial in reducing scale and biofilm adhesion and increasing corrosion resistance. Although most nonmetallic materials lack the high thermal conductivity of traditional metal options, they open up the possibility of alternate configurations such as polymeric hollow-fiber systems with heat-transfer coefficients that rival those of traditional heat exchangers. ${ }^{41}$ As with the other materials innovations discussed in this section, the possibility of using nonmetallic heat exchangers in power generation is still in the early stages, and a sustained and focused R\&D effort will be needed.

\section{Conclusions}

Water is, and will remain, a critical input to the power-generation process for the foreseeable future. Given the increasing demand on water resources from all sectors, significant innovations will be required to ensure that adequate supplies are available to meet both global and regional needs. Opportunities for materials research that helps address this challenge are numerous and diverse. Superalloys and ceramic-matrix composites to improve gas-turbine efficiency, hydrophobic and hydrophilic coatings to improve heat-exchanger performance, and lowcost materials for compact air-cooled condensers are a few examples. This article has proposed a framework for evaluating different technology options for reducing water use in power production, namely, calculating the cost of conserved water based on the change in levelized cost of electricity and improved specific water usage. The hope is that this article has provided guidance to the materials research community in identifying some of the most pressing needs and opportunities for innovation in this area. 


\section{A closer look at the global water footprint for electricity production}

Here we present the relative water footprints of different modes of electricity production and explore how the overall footprint could evolve in coming decades. In the figure, the area of each block corresponds to the projected water footprint for each power-generation mode. Separate blocks are shown for the footprint in 2007 and the projected increment by 2030 , based on projections from the EIA base-case scenario. ${ }^{9}$ The potential increment associated with adoption of carbon capture and storage (CCS) for coal and the projected reduction of liquid (oil) generation are also shown.

Several assumptions were used to construct this figure. First, the specific water requirements are weighted averages for each fuel source, based on available data for different modes (open-loop versus closed-loop) of cooling. Such data exist in detail only for fossil-fuel-based systems in the United States, so the U.S. distribution was assumed to apply globally. Because growth forecasts do not provide projections for changes in the distribution of cooling modes, current distributions were assumed to remain constant. Second, the utilization of the installed generating capacity ranges from $90 \%$ for baseload systems to $30 \%$ for intermittent sources, reflecting the complexity of matching real-time variations in demand. Finally, water requirements are sensitive to technology innovations that reduce the specific water use, as well as policy decisions such as emissions controls. Without specific projections for how these capacity factors or technologies might change in the future, we simply extrapolated from current values.

Several major trends emerge from the figure:

- Fossil-fuel-based generation (coal, natural gas, oil) dominates the overall water footprint and will continue to do so. Coal-based power comprises the single largest component of the installed base and is forecasted to grow significantly, primarily in China, where coal fuels $80 \%$ of power plants. Recent developments that can help manage the growing water demand in China include (1) consolidation of older, smaller units into larger, more thermally efficient plants; (2) use of lower-water-intensity designs (higher-efficiency pulverized-coal and integrated gasification combined-cycle plants); and (3) further deployment of air cooling in its arid northern regions (where air cooling had been installed on $35 \mathrm{GW}$ of capacity by 2008). ${ }^{10}$

- Carbon-capture technologies can significantly increase the water footprint of fossil-fuel-based power generation (see the CCS scenario in the figure). Currently available technologies such as solvent capture can double the water requirements. ${ }^{7}$ Some of this impact could be mitigated through the development of less water-intensive capture technologies.

- There is considerable uncertainty regarding the deployment of nuclear power. Nuclear-based generation was projected to grow in the EIA base case, but the Fukushima Daiichi nuclear disaster in Japan following the earthquake and tsunami in March 2011 has led to the shutdown of some existing facilities and the cancellation or postponement of others. ${ }^{11}$

- Renewable thermal (geothermal, concentrated solarthermal) power accounts for only a small part of the overall water footprint. The smaller scale of these systems (tens of megawatts) compared to fossil-fuel or nuclear plants results in more manageable heat rejection loads and allows for more extensive use of air cooling. 


\section{References}

1. N. Onat, H. Bayar, Renewable Sustainable Energy Rev. 14, 3108 (2010).

2. M. Hightower, S.A. Pierce, Nature 452, 285 (2008)

3. R. Pate, M. Hightower, C. Cameron, W. Einfeld, Overview of Energy-Water Interdependencies and the Emerging Energy Demands on Water Resources (Report SAND 2007-1349C, Sandia National Laboratories, Los Alamos, NM, 2007).

4. V.S. Arunachalam, E.L. Fleischer, MRS Bull. 33, 264 (2008).

5. A.E. Farrell, A.R. Gopal, MRS Bull. 33, 373 (2008).

6. M.A. Shannon, R. Semiat, MRS Bull. 33, 10 (2008).

7. J. Macknick, R. Newmark, G. Heath, K.C. Hallett, A review of operational water consumption and withdrawal factors for electricity generating technologies (Technical Report NREL/TP-6A20-50900, National Renewable Energy Laboratory, Golden, CO, March 2011).

8. V. Fthenakis, H.C. Kim, Renewable Sustainable Energy Rev. 14, 2039 (2010). 9. International Energy Outlook 2010 [Report DOE/EIA-0484(2010), Energy Information Administration, Washington, DC, 2010].

10. Reducing Freshwater Consumption at Coal-Fired Power Plants: Approaches Used Outside the United States (Report DOE/NETL-2011/1493, National Energy Technology Laboratory, Pittsburgh, PA, 2011).

11. M. Schneider, A. Froggatt, S. Thomas, Nuclear Power in a Post-Fukushima World: 25 Years After the Chernobyl Accident (World Watch Institute, Washington, DC, 2010).

12. Y. Yang, X. Guo, N. Wang, Energy 35, 4336 (2010).

13. K. Mulder, N. Hagens, B. Fisher, AMBIO: J. Hum. Environ. 39, 30 (2010).

14. Existing Plants, Emissions and Capture-Setting Water-Energy R\&D Program Goals (Report DOE/NETL-2009/1372, National Energy Technology Laboratory, Pittsburgh, PA, 2009).

15. J.R. Wolfe, R.A. Goldstein, J.S. Maulbetsch, C.R. McGowin, J. Contemp. Water Res. Educ. 143, 30 (2009).

16. M. Konter, M. Thumann, J. Mater. Process. Technol. 117, 386 (2001).

17. A. Voinov, H. Cardwell, J. Contemp. Water Res. Educ. 143, 17 (2009).

18. S. Powell, C. Loh, G. Peiyin, "Falling up! Water pricing must meet true costs," in Blue Books: Experts' views for expert investors (CLSA Asia-Pacific Markets, Hong Kong, 2010).

19. Department of Energy/National Energy Technology Laboratory's WaterEnergy Interface Research Program: December 2010 Update (National Energy Technology Laboratory, Pittsburgh, PA, 2010).
20. W.C. Micheletti, J.M. Burns, paper presented at the Water Issues in Fossil Energy Workshop, National Energy Technology Laboratory, Pittsburgh, PA, 27 June 2002. 21. Power Plant Water Usage and Loss Study (National Energy Technology Laboratory, Pittsburgh, PA, 2005).

22. P.J. Maziasz, I.G. Wright, J.P. Shingeldecker, T.B. Gibbons, R.R. Romanosky, paper presented at the 19th Annual Conference on Fossil Energy Materials (sponsored by the U.S. Department of Energy), Knoxville, TN, 9-11 May 2005.

23. P.J. Marto, D.J. Lookey, J.W. Rose, A.S. Wanniarachchi, Int. J. Heat Mass Transfer 29, 1109 (1986)

24. M.M. Gentleman, J.A. Ruud, Langmuir 26, 1408 (2010).

25. Power Generation Water Use in Texas for the Years 2000 to 2060: Final Report (Texas Water Development Board, Austin, TX, 2003).

26. F.J. Brooks, GE Gas Turbine Performance Characteristics (Report GER-3567H, GE Power Systems, Schenectady, NY, 2000)

27. N.P. Padture, M. Gell, E.H. Jordan, Science 296, 280 (2002).

28. G.S. Corman, K.L. Luthra, in Handbook of Ceramic Composites, N.P. Bansal, Ed. (Kluwer Academic Publishers, New York, 2005), pp. 99-115.

29. D.W. Richerson, Modern Ceramic Engineering: Properties, Processing, and Use in Design (CRC Press, Boca Raton, FL, 2006).

30. N.H. Menzler, F. Tietz, S. Uhlenbruck, H.P. Buchkremer, D. Stover, J. Mater Sci. 45, 3109 (2010)

31. Use of Non-Traditional Water for Power Plant Applications: An Overview of DOE/NETL R\&D Efforts (Report DOE/NETL-311/040609, National Energy Technology Laboratory, Pittsburgh, PA, 2009).

32. K.P. Lee, T.C. Arnot, D. Mattia, J. Membr. Sci. 370, 1 (2010).

33. D. Li, H. Wang, J. Mater. Chem. 20, 4551 (2010).

34. A. Kalra, S. Garde, G. Hummer, Proc. Natl. Acad. Sci. U.S.A. 100, 10175 (2003).

35. J.K. Holt, H.G. Park, Y. Wang, M. Stadermann, A.B. Artyukhin, C.P. Grigoropoulos, A. Noy, 0. Bakajin, Science 312, 1034 (2006).

36. M. Kumar, M. Grzelakowski, J. Zilles, M. Clark, W. Meier, Proc. Natl. Acad. Sci. U.S.A. 104, 20719 (2007).

37. R.M. Manglik, M.A. Jog, J. Heat Transfer 131, 121001 (2009).

38. L. Liu, A.M. Jacobi, J. Heat Transfer 131, 051802 (2009).

39. S. Krishnan, C.J. Weinman, C.K. Ober, J. Mater. Chem. 18, 3405 (2008).

40. H.T. El-dessouky, H.M. Ettouney, Desalination 122, 271 (1999).

41. D.M. Zarkadas, K.K. Sarkar, Ind. Eng. Chem. Res. 43, 8093 (2004).

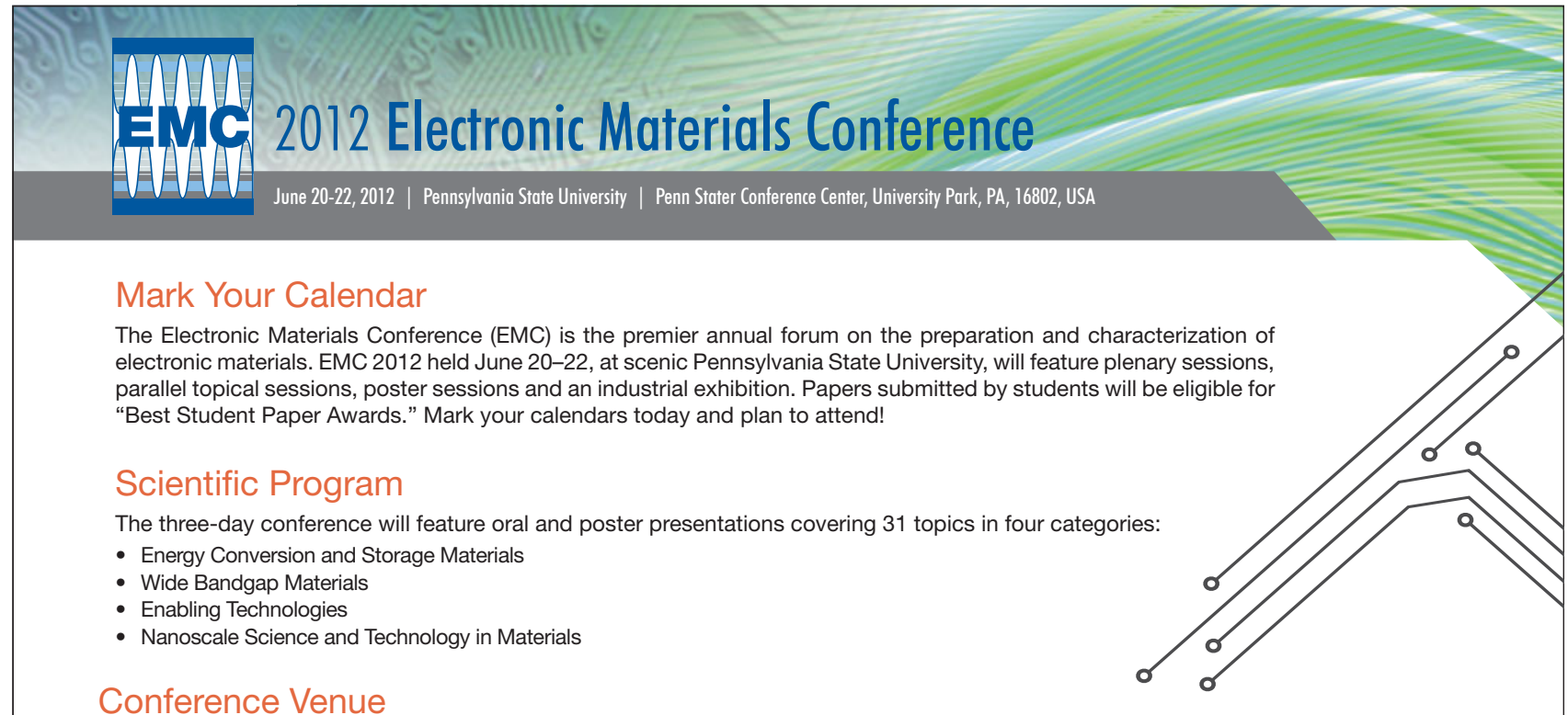

Pennsylvania State University (PSU) is consistently ranked one of the leading universities for materials science and engineering by the National Science Foundation, making it an ideal conference location. The campus is nestled among the beautiful Pennsylvania countryside, and is rich with trails to explore. From sightseeting to action-packed adventures, you won't want to miss a moment. After all, it's not called the "Happy Valley" for nothing! 


\section{CONFIDENCE COMES WITH GREAT RESULTS}
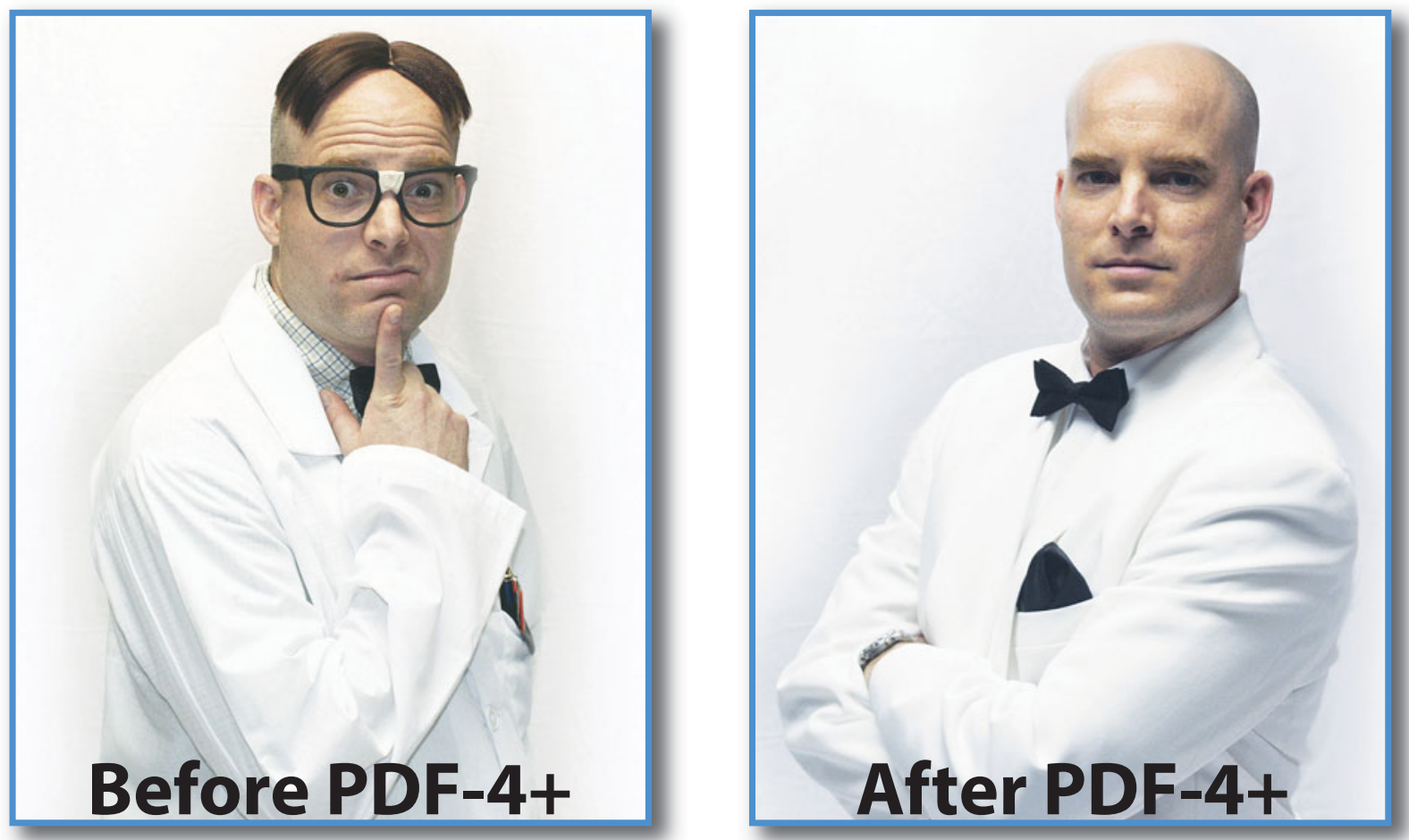

\section{$\mathrm{PDF}=4+2011$ \\ More Data • More Data Mining}

The most comprehensive collection of inorganic powder patterns

Phase identification using physical, chemical and crystallographic data

* Comprehensive materials database featuring 316,291 data sets

Standardized, edited data from four crystallographic databases

* Utilize quantitative analysis methods

160,183 Data sets with atomic parameters for Rietveld analysis

221,102 Data sets with $1 / I_{c}$ for Reference Intensity Ratio (RIR)

316,291 Data sets with full digital patterns for total pattern analysis

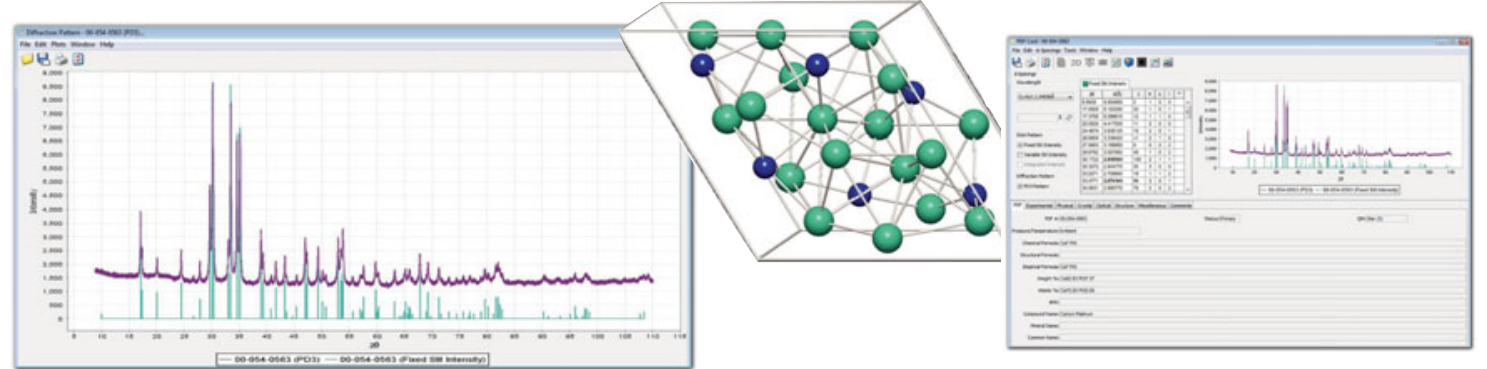

International Centre for Diffraction Data

Phone: 610.325.9814 / Toll-free U.S. \& Canada: 866.378.9331

marketing@icdd.com・www.icdd.com

ICDD, the ICDD logo and PDF are registered in the U.S. Patent \& Trademark Office.

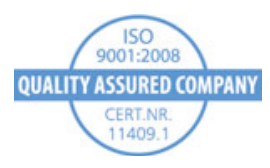

